University of Wollongong

Research Online

Faculty of Engineering and Information

Faculty of Engineering and Information

Sciences - Papers: Part B

Sciences

2018

\title{
Mechanical properties and microstructure of a Ti-6Al-4V alloy subjected to cold rolling, asymmetric rolling and asymmetric cryorolling
}

Hai Liang Yu

University of Wollongong, hailiang@uow.edu.au

Ming Yan

South University of Science and technology of China

Jintao Li

University of Wollongong, jl221@uowmail.edu.au

Ajit R. Godbole

University of Wollongong, agodbole@uow.edu.au

Cheng Lu

University of Wollongong, chenglu@uow.edu.au

See next page for additional authors

Follow this and additional works at: https://ro.uow.edu.au/eispapers1

Part of the Engineering Commons, and the Science and Technology Studies Commons

Research Online is the open access institutional repository for the University of Wollongong. For further information contact the UOW Library: research-pubs@uow.edu.au 


\title{
Mechanical properties and microstructure of a Ti-6Al-4V alloy subjected to cold rolling, asymmetric rolling and asymmetric cryorolling
}

\author{
Abstract \\ The mechanical properties of the Ti-6Al-4V alloy are significantly determined by the process used for \\ manufacture. In this study, the mechanical properties of the Ti-6Al-4V alloy manufactured using cold \\ rolling, asymmetric rolling and asymmetric cryorolling were characterized by subjecting it to the tensile \\ test and the microhardness test. The evolution in the microstructure was studied using scanning electron \\ microscopy, transmission electron microscopy as well as energy dispersive $\mathrm{X}$-ray spectrometry. Results \\ show that the Ti-6Al-4V alloy sheets subjected to asymmetrical cryorolling with low rolling speed ratio \\ between the upper and lower rolls have the highest tensile strength and microhardness. The tensile stress \\ of the alloy samples after cold rolling was found to be $1008 \mathrm{MPa}, 1046 \mathrm{MPa}$ after asymmetric rolling, and \\ $1113 \mathrm{MPa}$ after asymmetric cryorolling. The highest Vickers hardness (HV395) is achieved by \\ asymmetric cryorolling. We discuss the mechanical behavior using the criteria of grain size, size of \\ second phase as well as dislocation density.

\section{Disciplines} \\ Engineering | Science and Technology Studies

\section{Publication Details} \\ Yu, H., Yan, M., Li, J., Godbole, A., Lu, C., Tieu, K., Li, H. \& Kong, C. (2018). Mechanical properties and \\ microstructure of a Ti-6Al-4V alloy subjected to cold rolling, asymmetric rolling and asymmetric \\ cryorolling. Materials Science and Engineering A: Structural Materials: Properties, Microstructure and \\ Processing, 710 10-16.

\section{Authors} \\ Hai Liang Yu, Ming Yan, Jintao Li, Ajit R. Godbole, Cheng Lu, Anh Kiet Tieu, Hui Jun Li, and Charlie Kong
}




\section{Mechanical properties and microstructure of a Ti-6Al-4V alloy subjected to cold} rolling, asymmetric rolling and asymmetric cryorolling

Hailiang $\mathrm{YU}^{1,2,3,4^{*}}$, Ming $\mathrm{YAN}^{5 *}$, Jintao $\mathrm{LI}^{4}$, Ajit GODBOLE${ }^{4}$, Cheng $\mathrm{LU}^{4}$, Kiet $\mathrm{TIEU}^{4}$, Huijun $\mathrm{LI}^{4}$, Charlie KONG ${ }^{6}$

1. State Key Laboratory of High Performance Complex Manufacturing, Central South University, Changsha 410083, China; 2. School of Mechanical and Electrical Engineering, Central South University, Changsha 410083, China; 3. School of Metallurgy Engineering, Xi'an University of Architecture and Technology, Xi'an 710055, China; 4. School of Mechanical, Materials \& Mechatronics Engineering, University of Wollongong, NSW 2500, Australia; 5. Department of Materials Science and Engineering, South University of Science and Technology of China, Shenzhen 518055, China; 6. Electron Microscope Unit, University of New South Wales, Sydney, NSW 2052, Australia.

Abstract: The mechanical properties of the Ti-6Al-4V alloy are significantly determined by the process used for manufacture. In this study, the mechanical properties of the Ti-6Al-4V alloy manufactured using cold rolling, asymmetric rolling and asymmetric cryorolling were characterized by subjecting it to the tensile test and the microhardness test. The evolution in the microstructure was studied using scanning electron microscopy, transmission electron microscopy as well as energy dispersive X-ray spectrometry. Results show that the Ti-6Al-4V alloy sheets subjected to asymmetrical cryorolling with low rolling speed ratio between the upper and lower rolls have the highest tensile strength and microhardness. The tensile stress of the alloy samples after cold rolling was found to be $1008 \mathrm{MPa}, 1046 \mathrm{MPa}$ after asymmetric rolling, and 1113 MPa after asymmetric cryorolling. The highest Vickers hardness (HV395) is achieved by asymmetric cryorolling. We discuss the mechanical behavior using the criteria of grain size, size of second phase as well as dislocation density.

Keywords: Ti-6Al-4V alloy; asymmetric rolling; cryorolling; mechanical property; microstructure

\footnotetext{
*Corresponding author: YU HL, email: yuhailiang1980@tom.com, hailiang@uow.edu.au; YAN M., email:
} yanm@sustc.edu.cn 


\section{Introduction}

Titanium (Ti) alloys have attracted ever-increasing attention due to their suitability for military, aircraft, spacecraft and medical device applications. The Ti-6Al-4V alloy is one of the most utilized $\mathrm{Ti}$ alloys, accounting for more than $50 \%$ of total titanium usage. Ti-6Al-4V is the biomaterial of choice for many load bearing surgical implants, for it combines good biocompatibility with excellent mechanical strength and corrosion resistance [1].

In recent years, studies have shown that grain size refinement of the Ti-6Al-4V alloy results in greatly improving in mechanical properties. Li et al. [2] developed a nanograined (NG) layer with grain size 10-19 nm on the surface of a Ti-6Al-4V alloy sample using fast multiple rotation rolling. The high density of grain boundaries in the NG layer is beneficial to the formation of a passive film that results in improved corrosion resistance. Sonntag et al. [3] studied the fatigue performance of Ti-6Al-4V subjected to mechanical surface treatment. Compared to non-treated samples, all treatments introduced substantial compressive residual stresses and exhibited considerable potential for increasing the fatigue performance from $10 \%$ to $17.2 \%$ after laser shock peening. Cryogenic cooling allowed a reduction in the adhesive wear mechanism of Ti-6Al-4V used on the tool cutting surfaces [4]. Bertolini et al [5] found that cryogenic machining improves the corrosion and fretting corrosion resistance of Ti-6Al-4V alloy fabricated by additive manufacturing. Huang et al. [6] used thermo-hydrogen processing to improve the mechanical strength of Ti-6Al-4V from $930 \mathrm{MPa}$ to $1160 \mathrm{MPa}$. These studies suggest that processing techniques significantly affect the mechanical properties of Ti-6Al-4V alloys.

Asymmetric rolling is a special rolling technique in which shear deformation occurs in the rolling deformation zone [7]. Compared to traditional cold rolling, asymmetric rolling can reduce the rolling pressure and produce thinner metal sheets $[8,9]$. Tong et al. [8] found that the minimum thickness of sheets manufactured by asymmetric 
rolling is about $30 \%$ of those manufactured using cold rolling. Uniwersal et al. [9] found that increasing the asymmetric rolling speed ratio leads to higher $\Sigma 13$ shear stress and changes the texture orientation. Asymmetric cryorolling, in which liquid nitrogen is used to cool the metals, has been shown to improve the mechanical properties of aluminium sheets [10]. Yu et al. [11] found that aluminium alloy 6061 sheets processed by accumulative roll bonding followed by asymmetric cryorolling and ageing have superior mechanical properties compared to those processed by accumulative roll bonding only. However, it is noted that both asymmetric rolling and asymmetric cryorolling are mostly used in processing face center cubic (FCC) metals such as $\mathrm{Al}$ and $\mathrm{Cu}$. There have been scarcely any on the application of these techniques to fabricate hexagonal close-packed (HCP) metals like Ti and Ti alloys.

Ti-6Al-4V is an $(\alpha+\beta)$ dual-phase alloy whose microstructure is sensitive to the processing conditions [12]. In the present study, Ti-6Al-4V sheets were fabricated using three techniques: cold rolling, asymmetric rolling and asymmetric cryorolling. The mechanical properties and microstructure of the sheets were analyzed. Mechanical properties of Ti-6Al-4V alloys are correlated against their different grain sizes, dislocation densities and status of the precipitation phases.

\section{Experimental Investigation}

Ti-6Al-4V alloy sheets were studied in this investigation. The length, width and thickness of sheets were $250 \mathrm{~mm}, 60 \mathrm{~mm}$ and $1.5 \mathrm{~mm}$ respectively. The sheets were processed by cold rolling, asymmetric rolling and asymmetric cryorolling on a four-high multifunction rolling mill. After rolling, the thicknesses of Ti-6Al-4V sheets were reduced to $0.8 \mathrm{~mm}$. The material of the work rolls was Cr12 steel. The diameter of work rolls was $50 \mathrm{~mm}$. The work rolls were freshly polished before rolling, and the rolling experiments were carried out at dry friction. For cold rolling, the experiments were carried out at room temperature and the rolling speed of the upper roll was the same as the lower roll. For asymmetric rolling, the experiments were carried out at 
room temperature, and the rolling speed ratio between upper and lower rolls was set as 1.2. In asymmetric cryorolling, the sheets were cooled by liquid nitrogen for more than 8 min before rolling, and the rolling speed ratio between the upper and lower rolls was set as 1.2.

After rolling, the Ti-6Al-4V sheets were machined with parallel width $6 \mathrm{~mm}$ and parallel length $36 \mathrm{~mm}$ to test the mechanical properties. The mechanical properties were tested on an INSTRON machine with an initial strain rate of $1.0 \times 10^{-3} \mathrm{~s}^{-1}$. Each test was repeated three times for repeatability. In addition, the micro-hardness of the samples was measured with a Vickers hardness tester using a load of $5 \mathrm{~g}$ and a dwell time of $12 \mathrm{~s}$; each sample was tested five times.

The fracture surfaces of tensile test samples were analyzed by scanning electron microscopy (SEM). The focus iron beam (FIB) technique was used to prepare transmission electron microscopy (TEM) samples to study the cross sections in the rolling direction and across the thickness. The microstructures of the rolled samples were analyzed by TEM with the energy dispersive spectroscopy (EDS) system. The distribution of elements of the rolled samples was mapped by EDS. A GBC MMA X-ray diffractometer (XRD) with $\mathrm{Cu} \mathrm{K \alpha}$ radiation $(\lambda=1.5418 \AA)$ was used to measure the phase diffraction profiles of the sheets after rolling.

\section{Results}

Fig. 1 shows the mechanical properties of the processed Ti-6Al-4V sheets. Table 1 compares their mechanical properties with those of the standard Ti-6Al-4V ally sheets. Fig. 1b shows that the elongations of the tensile test samples fabricated using cold rolling, asymmetric rolling and asymmetric cryorolling are all larger than $10 \%$, similar to that of the standard Ti-6Al-4V alloy [6]. In addition, the elongation rate of cold-rolled sheets is slightly higher than that of other two kinds of sheets. In Fig. 1c, it is seen that the tensile stress of samples after cold rolling is $1008 \mathrm{MPa}, 1046 \mathrm{MPa}$ for 
asymmetric rolling, and $1113 \mathrm{MPa}$ for asymmetric cryorolling. Compared with the tensile stress of the standard Ti-6Al-4V alloy, the tensile stress increases by $12.4 \%$ in sheets fabricated using asymmetric rolling, and by $19.7 \%$ in sheets fabricated using asymmetric cryorolling. Fig. 1d shows the microhardness of the samples after different processes. When using cold rolling, the hardness of the samples is HV352. Asymmetric cryorolling increases the hardness of the samples to HV395. The hardness therefore shows a trend similar to the tensile stress among the three processing pathways.

Fig. 1. Mechanical properties of cold rolled, asymmetric rolled and asymmetric cryorolled Ti-6Al-4V sheets. (a) Engineering strain-stress curves, (b) elongations of sheets, (c) tensile stress of sheets, and (d) microhardness of sheets.

\section{Table 1. Comparison of mechanical properties of Ti-6Al-4V alloy}

Fig. 2 shows SEM fractography images of the tensile test samples. It is seen that the dimples in the cold rolled samples are slightly smaller those that in the asymmetric rolled and the asymmetric cryorolled samples. This implies that the ductility of the cold rolled Ti-6Al-4V sheets is slightly higher than that of other two kinds of sheets. In addition, the dimple depths are seen to be similar for the asymmetrical rolled and asymmetric cryorolled sheets. From Fig. 1b, we know that the elongation of asymmetric rolled sheets is nearly the same of the asymmetric cryorolled sheets. For the FCC metal sheets such as $\mathrm{Al}$ and $\mathrm{Cu}$ sheets, the ductility of cryorolled sheets is better than that of room-temperature rolled sheets $[13,14]$. For the HCP Ti-6Al-4V alloys, however, it appears that the influence of rolling temperature on the ductility of the sheets is negligible.

Fig. 2. SEM images of fracture surface after tensile test. (a) and (b) for cold rolling, (c) and (d) for asymmetric rolling, and (e) and (f) for asymmetric cryorolling. 
Fig. 3a-Fig.3c show the TEM bright-field images of the microstructure of the sheets after cold rolling, asymmetric rolling and asymmetric cryorolling respectively. The figures suggest that the typical microstructures of the samples are dominated by elongated $\alpha$-Ti phases with high density of tangled dislocation cells. In addition, the thin lamella-shaped grains in the asymmetric cryorolled sheets are smaller than those in the cold-rolled sheets and asymmetric rolled sheets. This is consistent with the observation that the Ti-6Al-4V alloy subjected to asymmetric cryorolling shows the best yield stress.

Fig. 3. TEM images of (a) cold rolled, (b) asymmetric rolled and (c) asymmetric cryorolled samples.

Figs. 4-6 show EDS images of the elemental distribution in samples after cold rolling, asymmetric rolling and asymmetric cryorolling respectively. There is seen to be very little difference in the distribution of the $\mathrm{Ti}$ and $\mathrm{Al}$ elements. However, the $\mathrm{V}$ element, which is rich in the $\beta$-Ti phase, shows a different distribution among the three processing pathways, suggesting different morphogens and/or grain size of the $\beta-\mathrm{Ti}$ phase. Fig. 4 shows that the $\mathrm{V}$ element enriched particles (i.e. the $\beta$-Ti phase) assembles with large size. In Fig. 5 this element appears in a laminate structure of finer size. In Fig. 6, the V element-enriched particles (i.e. the $\beta$-Ti phase) are seen to be much smaller than those in above two cases. Table 2 lists the mean thicknesses of the V element-enriched regions: $333.3 \mathrm{~nm}, 245.3 \mathrm{~nm}$ and 101.3 for cold rolling, asymmetric rolling and asymmetric cryorolling respectively.

Fig. 4. EDS images of element distribution in cold rolled sample. (a) Ti element, (b) Al element, (c) $\mathrm{V}$ element and (d) combination of Ti, $\mathrm{Al}$ and $\mathrm{V}$.

Fig. 5. EDS images of element distribution in asymmetric rolled sample. (a) Ti element, (b) Al element, (c) V element and (d) combination of Ti, Al and V. 
Fig. 6. EDS images of element distribution in asymmetric cryorolled sample. (a) Ti element, (b) Al element, (c) V element and (d) combination of Ti, Al and V.

Table 2. Thickness of $\mathrm{V}$ element assemble regions

\section{Discussion}

In Fig. 1, it is seen that the yield stress and microhardness of Ti-6Al-4V sheets fabricated by asymmetric cryorolling are higher than those of the sheets fabricated by asymmetric rolling and cold rolling. For metal alloys, there are methods which can improve the mechanical properties based on the mechanisms of manipulating grain refinement, size of second phase, and dislocation density. In the following sections, we focus on the effect of these three mechanisms on the mechanical properties of the Ti-6Al-4V sheets.

(1) Grain refinement. According to the Hall-Patch equation, the yield stress of metals increases with finer grain size [15]. For the Ti-6Al-4V alloys, the mechanical strength increases with a reduction in grain size [16]. Liu et al. [16] found that the microhardness of Ti-6Al-4V alloy processed by high pressure surface rolling with grain size $21.8 \pm 4.4 \mathrm{~nm}$ reaches $490 \mathrm{HV}$, while the microhardness for the coarse-grained zone is merely $340 \mathrm{HV}$. The equal channel angular press [17-19] and high pressure torsion [20-22] techniques are also widely used to bring about grain refinement to produce high-quality micro-parts. Semenova et al. [18] studied the high-cycle fatigue behavior of a Ti-6Al-4V alloy subjected to a combination of equal channel angular pressing and extrusion. They found that the fatigue endurance of the alloy is almost $40 \%$ higher as compared to the alloy with a bimodal microstructure. Sergueeva et al. [21] found that the HPT-processed Ti-6Al-4V alloy shows

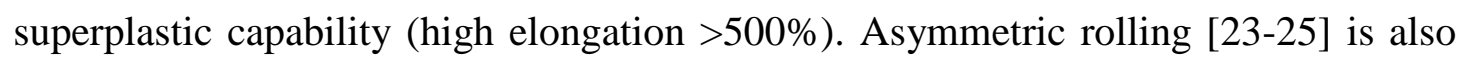
considered to be a severe plastic deformation technique used to produce ultrafine grained metals. The technique can produce metal foils that are $\sim 66 \%$ thinner than 
those produced by traditional symmetric rolling [8]. During asymmetric rolling, the additional shear strain contributes to the grain refinement. This feature has been widely used to produce ultrafine-grained aluminium alloys. Chao et al. [25] found that asymmetric rolling results in a great grain refinement in a Ti-6Al-4V alloy compared against symmetric rolling. This finding is in good agreement with our research as shown in Fig. 3a and Fig. 3b. When the asymmetric rolling reduction ratio reaches 70\%, ultrafine-grained microstructure can be obtained. Cryorolling [26-29] has been used to produce ultrafine-grained light metals such as aluminium and copper sheets. During cryorolling, the low temperature can effectively suspend the movement of dislocations and contribute to grain refinement. Zherebtsov et al. [28] found that rolling to a true thickness strain of 2.66 results in a grain size of $\sim 80 \mathrm{~nm}$ by cryorolling at $77 \mathrm{k}$ and $\sim 200 \mathrm{~nm}$ by cold rolling at $\sim 293 \mathrm{~K}$. Asymmetric cryorolling $[30,31]$ is a technique that combines features of asymmetric rolling and cryorolling. This technique can produce ultrafine-grained metals. Fig. 3 clearly shows that asymmetric cryorolling results in the finest grains in the Ti-6Al-4V sheets.

(2) Size of the second phase. Fig. 7a shows that the main phases in Ti-6Al-4V alloys subjected to the different processing techniques are $\alpha$-Ti and $\beta$-Ti. The strength and ductility of dual-phase metals can reach high values [32, 33]. Recently, Li et al [32] reported a dual-phase alloy which overcomes the strength-ductility trade-off. To improve the mechanical properties of alloys, it is important to control the size of the secondary phase, which is the $\beta$-Ti phase for the present alloys. Figs. 4-6 show that the thickness of the $\mathrm{V}$ element-rich regions (i.e. the $\beta$-Ti phase) in the alloy manufactured using asymmetric cryorolling is much smaller than that in other two cases. This also contributes to the improvement in material strength. Zherebtsove et al. [34] studied the microstructure evolution of commercial pure Ti during cryorolling and room temperature. The twin thickness and spacing between twins in Ti by cold rolling are $2.3 \mu \mathrm{m}$ and $7.9 \mu \mathrm{m}$ (thickness strain 0.1), $1.9 \mu \mathrm{m}$ and $6.5 \mu \mathrm{m}$ (thickness strain 0.22 ) and $2.2 \mu \mathrm{m}$ and $5.9 \mu \mathrm{m}$ (thickness strain 0.36 ), which are reduced to 1.2 $\mu \mathrm{m}$ and $3.5 \mu \mathrm{m}$ (thickness strain 0.1), $1.0 \mu \mathrm{m}$ and $3.0 \mu \mathrm{m}$ (thickness strain 0.22 ) and 
$0.7 \mu \mathrm{m}$ and $2.8 \mu \mathrm{m}$ (thickness strain 0.36 ) by cryorolling. The ultimate tensile strength of 900 MPa by cold rolling was improved to 1100 MPa by cryorolling. Fig. 7b shows that the XRD peak whose $2 \theta$ angle is $\sim 40^{\circ}$ gradually reduces if we compare among the from before rolling, cold rolling, asymmetric rolling and asymmetric cryorolling, implying that the size of the dominant $\alpha$-Ti phase gradually reduces.

\section{Fig. 7. (a) XRD results of the main phases of Ti-6Al-4V after different} processes, (b) XRD results of Ti-6Al-4V for $39.5^{\circ}-41.0^{\circ}$.

(3) Dislocation density. A higher dislocation density in metals is usually associated with higher strength [35]. During deformation, the total dislocation density $\left(\rho_{\mathrm{t}}\right)$ can be expressed in terms of a relatively low cell dislocation density $\left(\rho_{\mathrm{c}}\right)$ and a relatively higher cell wall dislocation density $\left(\rho_{w}\right)$ :

$$
\rho_{t}=f \rho_{w}+(1-f) \rho_{c}
$$

The following two equations describe the dislocation density evolution rates in the cell interiors $\left(\dot{\rho}_{\mathrm{c}}\right)$ and cell walls $\left(\dot{\rho}_{w}\right)[36]$,

$$
\begin{aligned}
& \dot{\rho}_{c}=\alpha^{*} \frac{1}{\sqrt{3} b} \sqrt{\rho_{w}} \dot{\gamma}_{w}^{r}-\beta^{*} \frac{6}{b d(1-f)^{1 / 3}} \dot{\gamma}_{c}^{r}-k_{0}\left(\frac{\dot{\gamma}_{c}^{r}}{\dot{\gamma}_{0}}\right)^{-1 / n} \rho_{c} \dot{\gamma}_{c}^{r} \\
& \left.\dot{\rho}_{w}=\beta^{*} \frac{\sqrt{3}(1-f)}{f b} \sqrt{\rho_{w}} \dot{\gamma}_{c}^{r}+\beta^{*} \frac{6(1-f)^{2 / 3}}{b d f} \dot{\gamma}_{c}^{r}-k_{0}\left(\frac{\dot{\gamma}_{w}^{r}}{\dot{\gamma}_{0}}\right)^{-1 / n} \rho_{w} \dot{\gamma}_{w}^{r}\right)
\end{aligned}
$$

where $\alpha^{*}$ and $\beta^{*}$ are dislocation evolution rate control parameters for the material; $f$ is the volume fraction of the dislocation cell wall; $b$ is the magnitude of the Burgers vector of the material, and $n$ is a temperature sensitivity parameter:

$$
n=\frac{B}{T}
$$

Here $B$ is a material parameter, $T$ is temperature; $k_{0}$ is the dislocation annihilation rate parameter,

$$
k_{0}=1.334 \times 10^{-5} T^{2}-1.176 \times 10^{-3} T+6.14
$$


Shi et al. [37] reported that the increase in the dislocation density results in enhanced strength and the motion of pre-existing high-density dislocations at high stress through forming nanoscale subgrains in ductility enhanced cryorolled Zr. He et al. [38] reported that a high dislocation density in deformed and partitioned steel results in large ductility and high strength. Hu et al. [23] reported that the HPT-deformed Ti-6Al-4V alloys contain a high density of dislocations which contribute to high mechanical properties. Compared with room-temperature rolling, rolling at cryogenic temperature would suppress the dislocation mobility and contribute to grain refinement. Tang et al. [39] found that the surface integrity and corrosion resistance of a cryogenic burnished Ti-6Al-4V alloy increase greatly due to its high density of grain boundary and dislocations. Eqs. (1)-(5) suggest that dislocation density during deformation increases with higher shear strain and lower temperature. Consistent with this prediction, the apparent dislocation cell density in Ti-6Al-4V alloy subjected to asymmetric cryorolling was observed to be higher than that resulting from asymmetric rolling, and it is lowest in the alloy subjected to cold rolling with the same rolling reduction. Thus, it can be concluded that the high dislocation density also contributes to the improvement in mechanical properties of the Ti-6Al-4V subjected to the asymmetric cryorolling.

\section{Conclusions}

(1) Ti-6Al-4V alloy sheets were manufactured using cold rolling, asymmetric rolling and asymmetric cryorolling. The alloy fabricated using asymmetric cryorolling shows the highest strength and microhardness compared with the other two processing techniques.

(2) EDS mapping results clearly show that cold rolling, asymmetrical rolling and asymmetric cryorolling lead to a shrinking of the $\mathrm{V}$ element-rich regions (i.e. the $\beta$-Ti phase). The mean thicknesses of $\mathrm{V}$ element-rich regions were seen to be $333.3 \mathrm{~nm}$, $245.3 \mathrm{~nm}$ and 101.3 for cold rolling, asymmetric rolling and asymmetric cryorolling respectively. 
(3) Smaller grain size, smaller size of the second phase and higher dislocation density may contribute to an improvement in the mechanical properties of the Ti-6Al-4V alloy subjected to the asymmetric cryorolling.

\section{Acknowledgements}

This research was supported by National Natural Science Foundation of China (Grant number: 51674303), Australian Research Council Discovery Project (Grant number: DP170103092) and the Research Fund of the Key Laboratory of High Performance Complex Manufacturing, Central South University, China (ZZYJKT2017-04).

\section{References}

[1] Lieblich M., Barriuso S., Multigner M., González-Doncel G., González-Carrasco J.L. Thermal oxidation of medical Ti6Al4V blasted with ceramic particles: effects on the microstructure, residual stresses and mechanical properties. Journal of the Mechanical Behavior of Biomedical Materials, 2016, 54:173-184.

[2] Li Y., Sun K., Liu P., Liu Y., Chui P. Surface nanocrystallization induced by fast multiple rotation rolling on Ti-6Al-4V and its effect on microstructure and properties. Vacuum, 2014, 101: 102-106.

[3] Sonntag R., Reinders J., Gibmeier J., Kretzer J.P. Fatigue performance of medical Ti6Al4V alloy after mechanical surface treatments. Plos One, 2015,10: 0121963.

[4] Bordin A., Bruschi S., Ghiotti A., Bariani P.F. Analysis of tool wear in cryogenic machining of additive manufactured Ti6Al4V alloy. Wear, 2015, 328-329: 89-99.

[5] Bertolini R., Bruschi S., Bordin A., Ghiotti A., Pezzato L., Dabalã. Fretting corrosion behavior of additive manufactured and cryogenic-machined Ti6Al4V for biomedical applications. Advanced Engineering Materials, 2016, DOI: 10.1002/adem.201500629.

[6] Huang S., Zong Y., Shan D. Application of thermohydrogen processing to 
Ti6Al4V alloy blade isothermal forging. Materials Science and Engineering A, 2013, 561: 17-25.

[7] Yu H.L., Lu C., Tieu K., Li H.J., Godbole A., Zhang S.H. Special rolling techniques for improvement of mechanical properties of ultrafine-grained metal sheets: A review. Advanced Engineering Materials, 2016, 18: 754-769.

[8] Tang D., Liu X., Song M., Yu H.L. Experimental and theoretical study on minimum achievable foil thickness during asymmetric rolling. Plos One, 2014, 9: e106637.

[9] Uniwersal A., Wróbel M., Wierzbanowski K., Wroński S., Wroński M., Kalemba-Rec I., Sak T., Bacroix B. Microstructure, texture and mechanical charactersitics of asymmetrically rolled polycrystalline copper. Materials Characterization, 2016, 118: 575-583.

[10] Yu H.L., Lu C., Tieu K., Liu X., Sun Y., Yu Q.B., Kong C. Asymmetrical cryorolling for fabrication of nanostructured aluminium sheets. Scientific Reports, 2012, 2: 772 .

[11] Yu H.L., Su L.H., Lu C., Tieu K., Li H.J., Li J.T., Godbole A., Kong C. Enhanced mechanical properties of ARB-processed aluminum alloy 6061 sheets by subsequent asymmetric cryorolling and ageing. Materials Science and Engineering A, 2016, 674: 256-261.

[12] Fernandez-Zelaia P., Melkote S., Marusich T., Usui S. A microstructure sensitive grain boundary sliding and slip based constitutive model for machining of Ti-6Al-4V. Mechanics of Materials, 2017, 109: 67-81.

[13] Ocid'Ko I.A., Langdon T.G. Enhanced ductility of nanocrystalline and ultrafine-grained metals. Reviews on Advanced Materials Science, 2012, 30: 103-111.

[14] Wang Y., Chen M., Zhou F., Ma E. High tensile ductility in a nanostructured metal. Nature, 2002, 419; 912-915.

[15] Balasubramanian N., Langdon T.G. The strength-grain size relationship in ultrafine-grained metals. Metallurgical and Materials Transactions A, 2016, 47: $5827-5838$. 
[16] Liu M., Li J.Y., Ma Y., Yuan T.Y., Mei Q.S. Surface nanocrystallization and property of Ti6Al4V alloy induced by high pressure surface rolling. Surface and Coatings Technology, 2016, 289: 94-1000.

[17] Valiev R.Z., Langdon T.G. Principles of equal-channel angular pressing as a processing tool for grain refinement. Progress in Materials Science, 2006, 51: 881-981.

[18] Semenova I.P., Polyakov A.V., Polyakova V.V., Huang Y., Valiev R.Z., Langdon T.G. High-cycle fatigue behavior of an ultrafine-grained Ti-6Al-4V alloy processed by ECAP and extrusion. Advanced Engineering Materials, 2016, 18: 2057-2062.

[19] Shi Q., Tse Y.Y., Higginson R.L. Effects of processing parameters on relative density, microhardness and microstructure of recycled Ti-6Al-4V from machining chips produced by equal channel angular pressing. Materials Science and Engineering A, 2016, 651: 248-258.

[20] Zhilyaev A.P., Langdon T.G. Using high-pressure torsion for metal processing: fundamentals and applications. Progress in Materials Science, 2008, 53: 893-979.

[21] Sergueeva A.V., Stolyarov V.V., Valiev R.Z., Mukherjee A.K. Superplastic behavior of ultrafine-grained Ti-6Al-4V alloys. Materials Science and Engineering A, 2002, 323: 318-325.

[22] Hu Z.Y., Cheng X.W., Zhang Z.H., Wang H., Li S.L., Korznikova G.F., Gunderov D.V., Wang F.C. The influence of defect structures on the mechanical properties of Ti-6Al-4V alloys deformed by high-pressure torsion at ambient temperature. Materials Science and Engineering A, 2017, 684: 1-13.

[23] Jiang J., Ding Y., Zuo F., Shan A. Mechanical properties and microstructures of ultrafine-grained pure aluminum by asymmetric rolling. Scripta Materialia, 2009, 60: 905-908.

[24] Wu X., Yang M., Yuan F., Wu G., Wei Y., Huang X., Zhu Y. Heterogeneous lamella structure unites ultrafine-grain strength with coarse-grain ductility. Proceedings of the National Academy of Sciences of the United States of America, 2015, 112: 14501-14505.

[25] Chao Q., Hodgson P.D., Beladi H. Microstructure and texture evolution during 
symmetric and asymmetric rolling of a martensitic Ti-6Al-4V alloy. Metallurgical and Materials Transactions A, 2016, 47: 531-545.

[26] Yu H.L., Lu C., Tieu K., Li H.J., Godbole A., Liu X., Kong C. Enhanced materials performance of $\mathrm{Al} / \mathrm{Ti} / \mathrm{Al}$ laminate sheets subjected to cryogenic roll bonding. Journal of Materials Research, 2017, DOI: 10.1557/jmr.2017.355.

[27] Shanmugasundaram T., Murty B.S., Subramanya Sarma V. Development of ultrafine grained high strength Al-Cu alloy by cryorolling. Scripta Materialia, 2006, 54: 2013-2017.

[28] Zherebtsov S.V., Dyakonov G.S., Salem A.A., Sokolenko V.I., Salishchev G.A., Semiatin S.L. Formation of nanostructures in commercial-purity titanium via cryorolling. Acta Materialia, 2013, 61: 1167-1178.

[29] Yang D.K., Cizek P., Fabijanic D., Wang J.T., Hodgson P.D. Work hardening in ultrafine-grained titanium: multilayering and grading. Acta Materialia, 2013, 61: 2840-2852.

[30] Yu H.L., Tieu K., Lu C., Lou Y., Liu X., Godbole A., Kong C. Tensile fracture of ultrafine grained aluminum 6061 sheets by asymmetric cryorolling for microforming. International Journal of Damage Mechanics, 2014, 23: 1077-1095.

[31] Yu H.L., Tieu K., Lu C., Liu X., Liu M., Godbole A., Kong C., Qin Q. A new insight into ductile fracture of ultrafine-grained Al-Mg alloys. Scientific Reports, 2015, 5: 9568.

[32] Li Z., Pradeep K.G., Deng Y., Raabe D., Tasan C.C. Metastable high-entropy dual-phase alloys overcome the strength-ductility trade-off. Nature, 2016, 534: 227-230.

[33] Yu H.L., Yan M., Lu C., Tieu K., Li H.J., Zhu Q., Godbole A., Li J.T., Su L.H., Kong C. Superstrength of nanograined steel with nanoscale intermetallic precipitates transformed from shock-compressed martensitic steel. Scientific Reports, 2016, 6: 36810.

[34] Zherebtsov S.V., Dyakonov G.S., Salem A.A., Sokolenko V.I., Salishchev G.A., Semiatin S.L. Formation of nanostructures in commercial-purity titanium via cryorolling. Acta Materialia, 2013, 61, 1167-1178. 
[35] Li X., Lu K. Playing with defects in metals. Nature Materials, 2017, 16: 700-701.

[36] Ding H., Shin Y.C. Dislocation density-based grain refinement modeling of orthogonal cutting of commercially pure titanium. Journal of Manufacturing Science and Engineering, Transactions of the ASME, 2014, 136: 041003.

[37] Shi Y. D., Li M., Guo D. F., Ma T. Y., Zhang Z. B., Li X. H., Zhang G. S., Zhang X. Y. Extraordinary toughening by cryorolling in Zr. Advanced Engineering Materials, 2014, 16: 167-170.

[38] He B.B., Hu B., Yen H.W., Cheng G.J., Wang Z.K., Luo H.W., Huang M.X. High dislocation density-induced large ductility in deformed and partitioned steels. Science, 2017, doi: 10.1126/science.aan0177.

[39] Tang J., Luo H.Y., Zhang Y.B. Enhancing the surface integrity and corrosion resistance of Ti-6Al-4V titanium alloy through cryogenic burnishing. International Journal of Advanced Manufacturing Technology, 2017, 88: 2785-2793. 

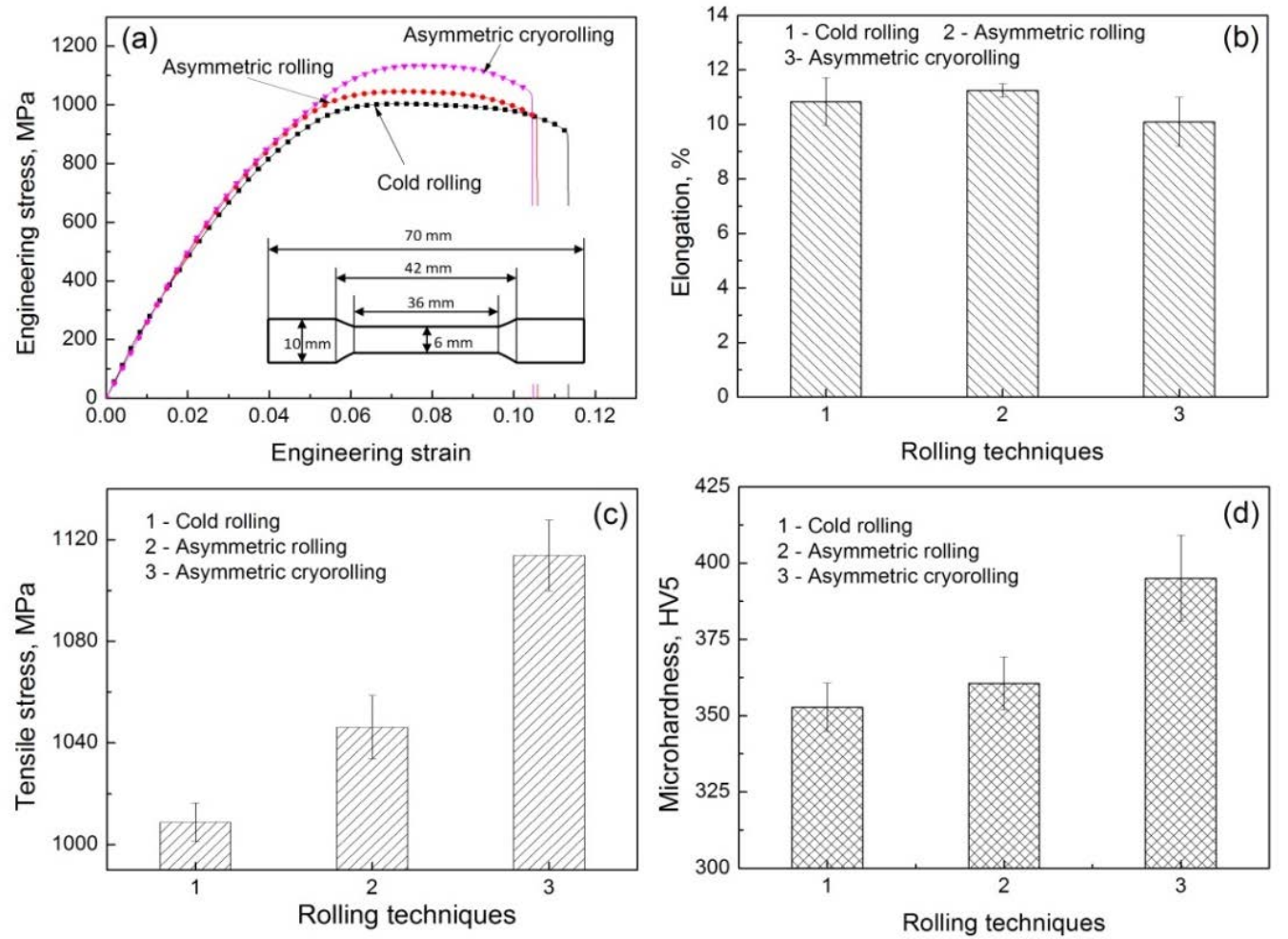

Fig. 1. Mechanical properties of cold rolled, asymmetric rolled and asymmetric cryorolled Ti-6Al-4V sheets. (a) Engineering strain-stress curves, (b) elongations of sheets, (c) tensile stress of sheets, and (d) microhardness of sheets. 

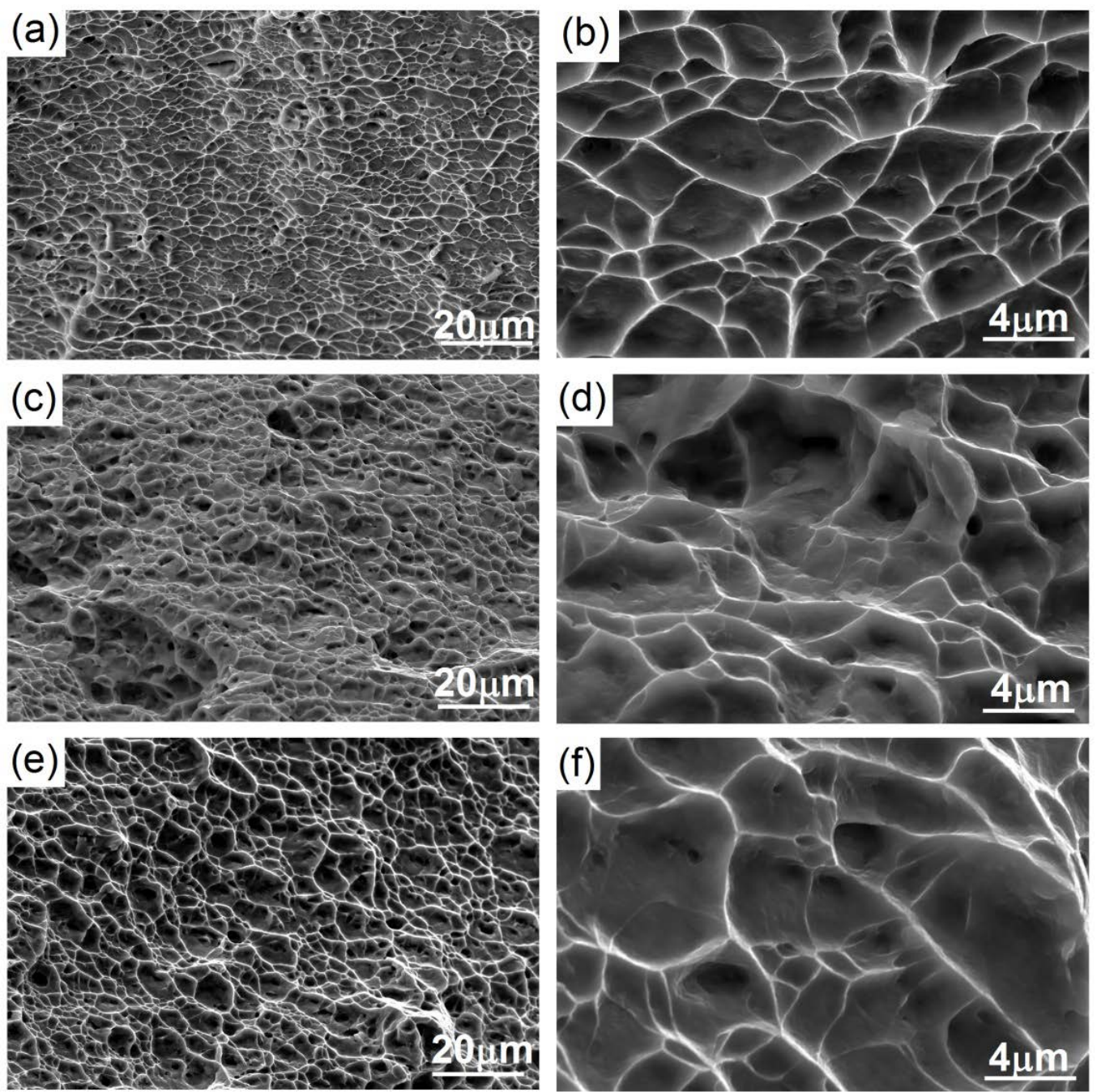

Fig. 2. SEM images of fracture surface after tensile test. (a) and (b) for cold rolling, (c) and (d) for asymmetric rolling, and (e) and (f) for asymmetric cryorolling. 

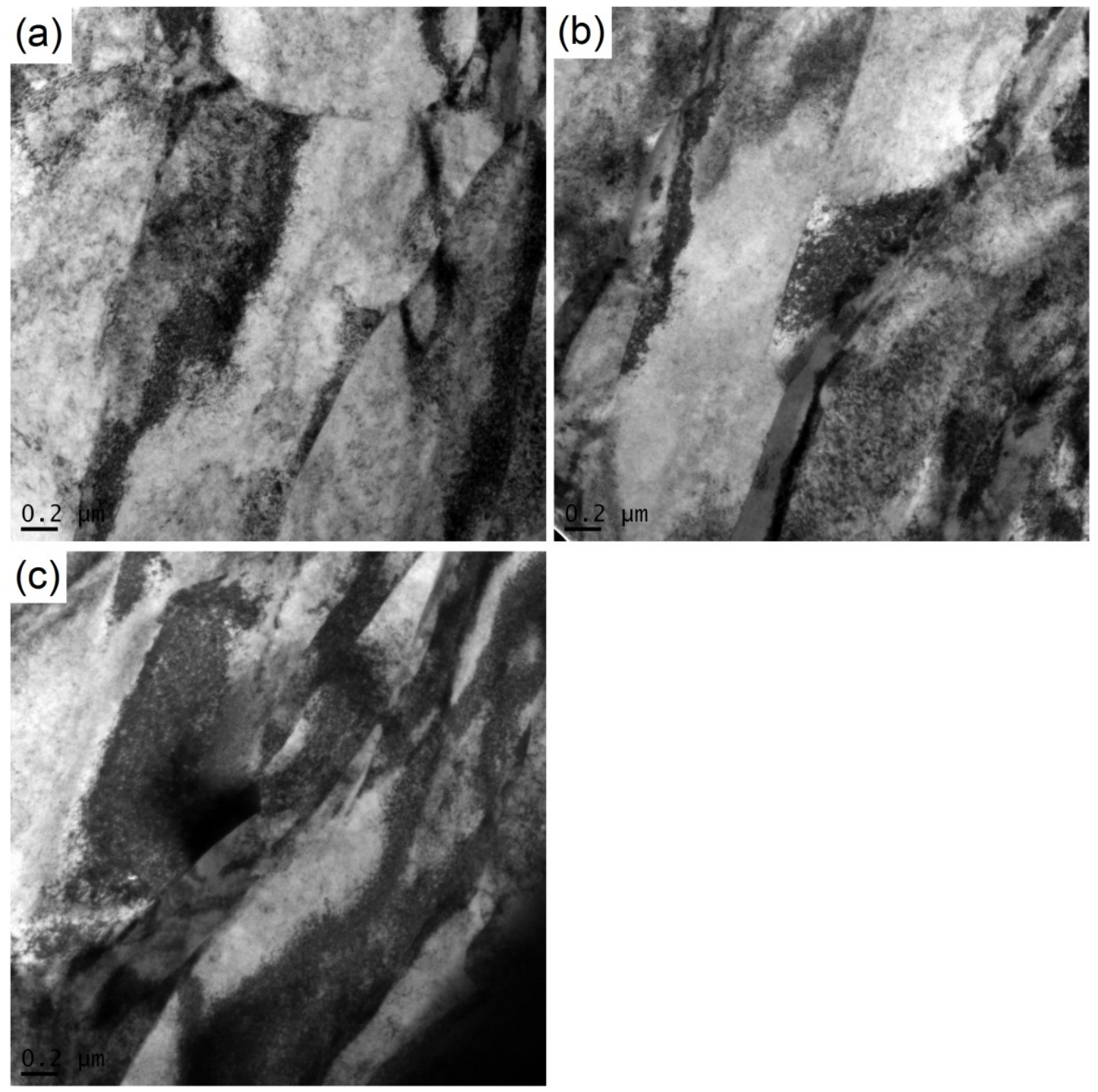

Fig. 3. TEM images of (a) cold rolled, (b) asymmetric rolled and (c) asymmetric cryorolled samples. 


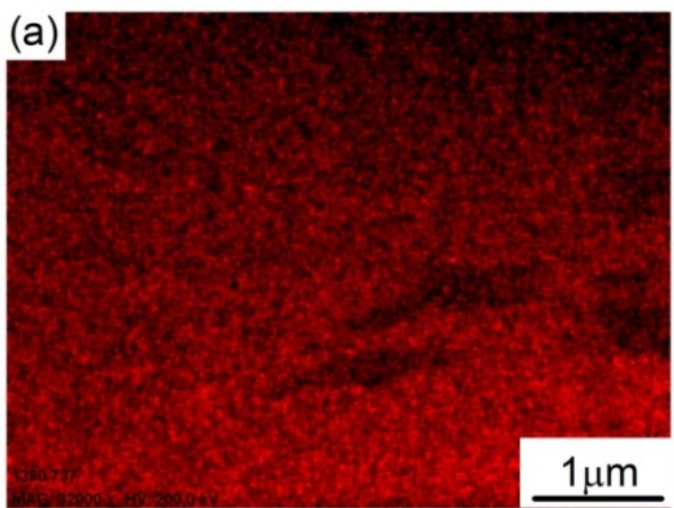

(c)

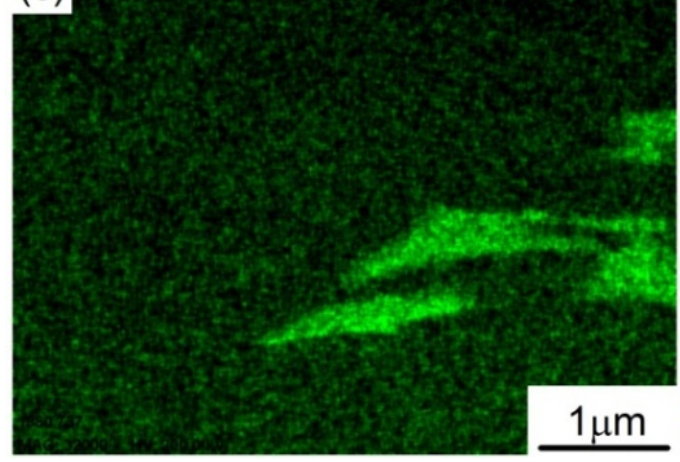

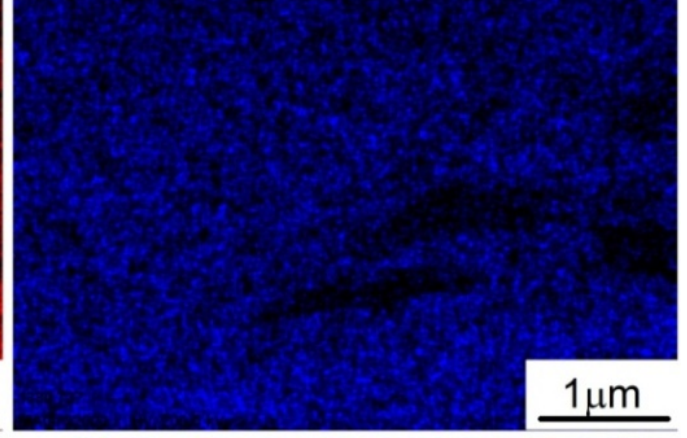

(d)

BE 过 M AI

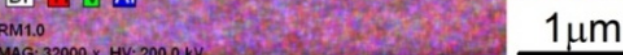

Fig. 4. EDS images of element distribution in cold rolled sample. (a) Ti element,

(b) Al element, (c) V element and (d) combination of Ti, Al and V. 

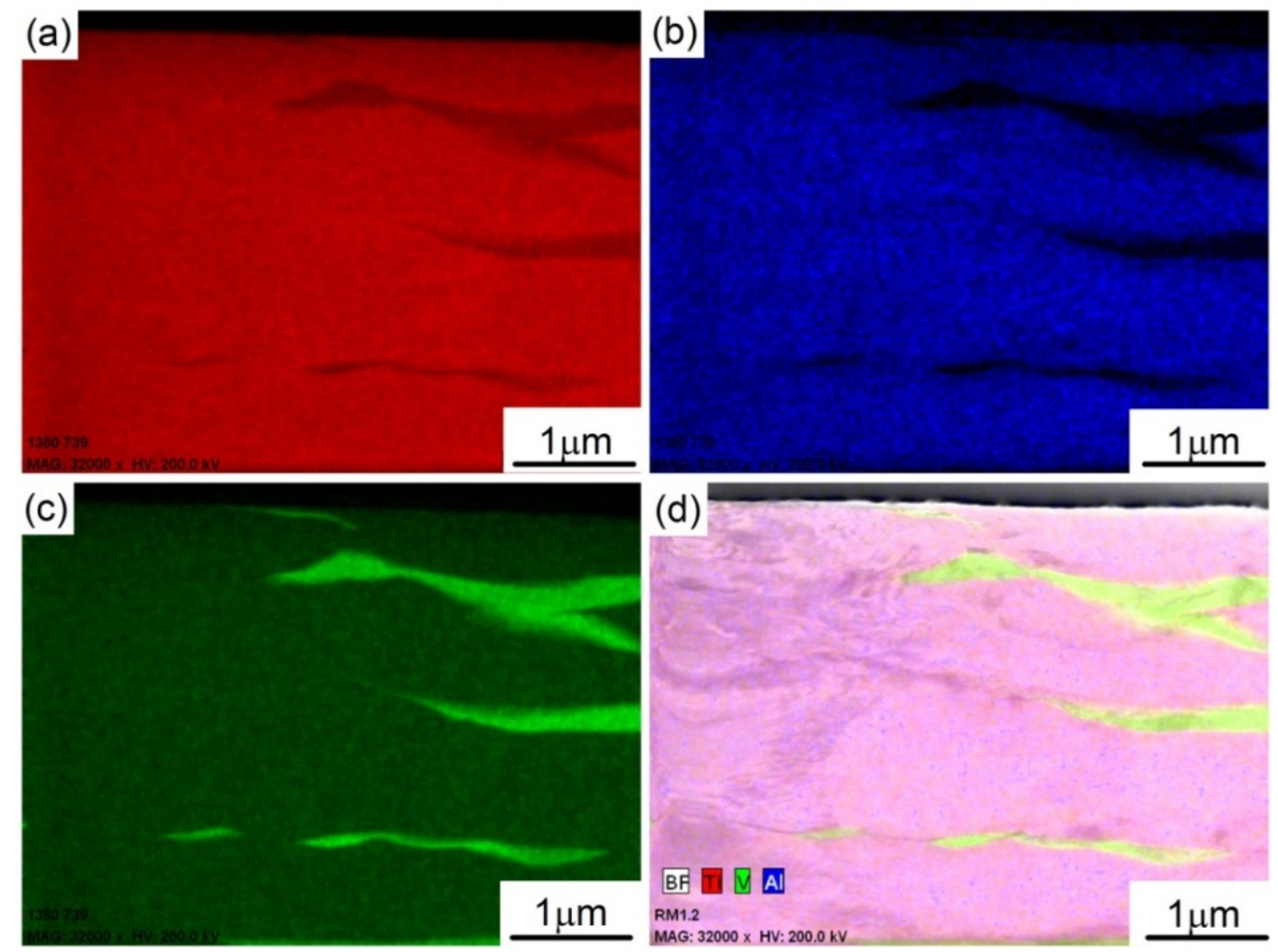

Fig. 5. EDS images of element distribution in asymmetric rolled sample. (a) Ti element, (b) Al element, (c) V element and (d) combination of Ti, Al and V. 

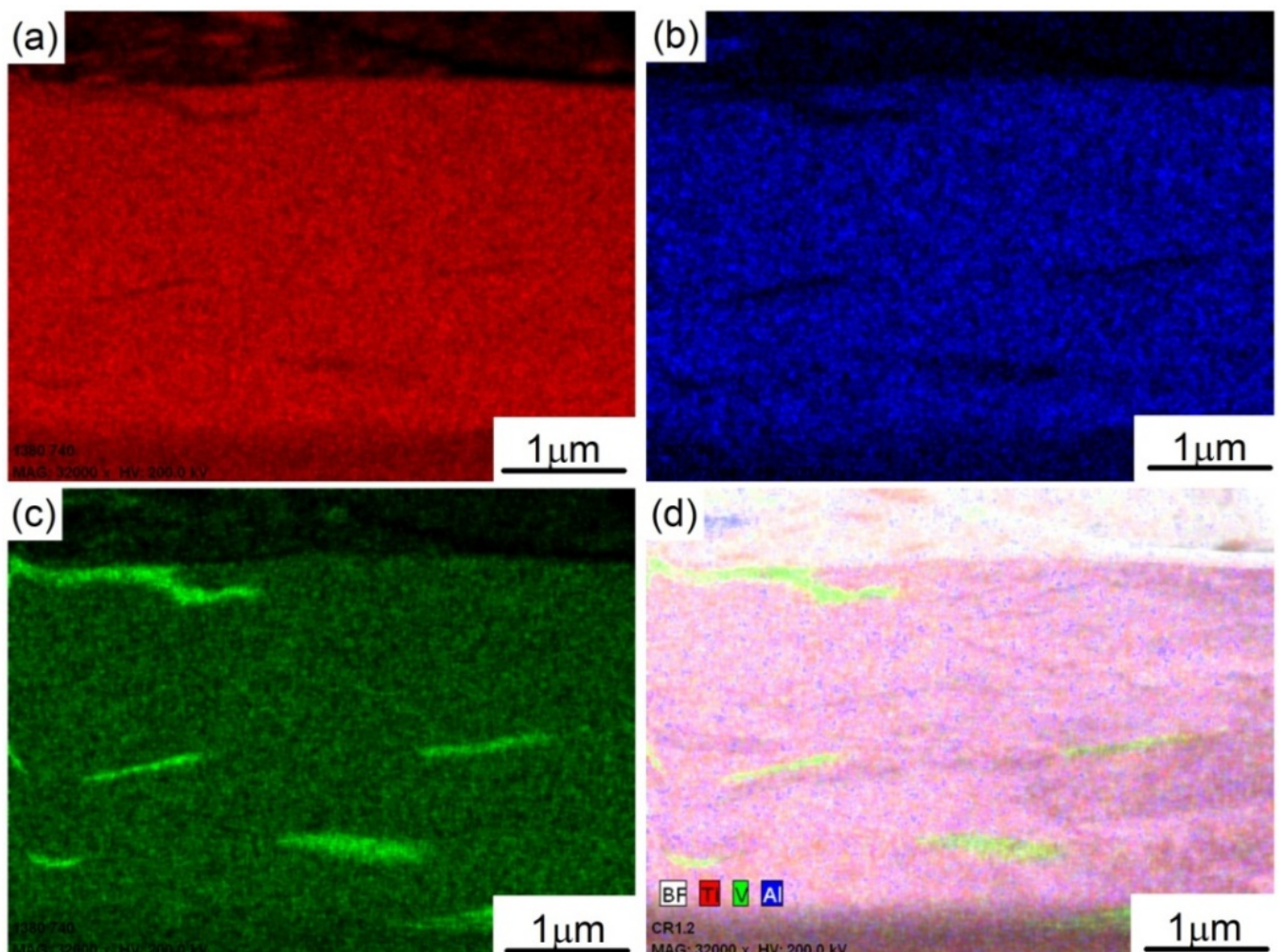

(d)

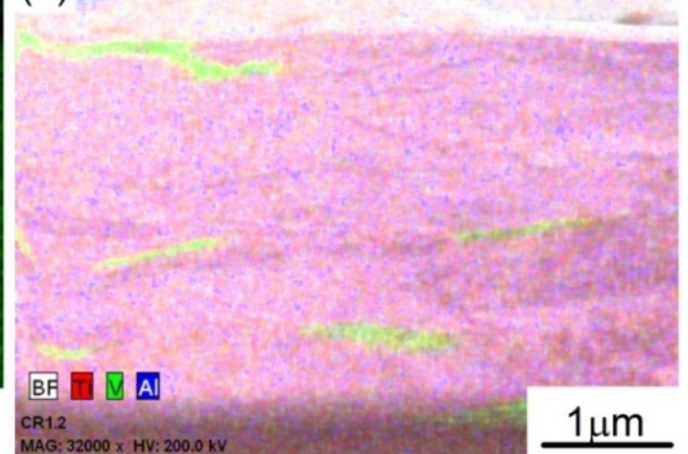

Fig. 6. EDS images of element distribution in asymmetric cryorolled sample. (a) Ti element, (b) Al element, (c) V element and (d) combination of Ti, Al and V. 

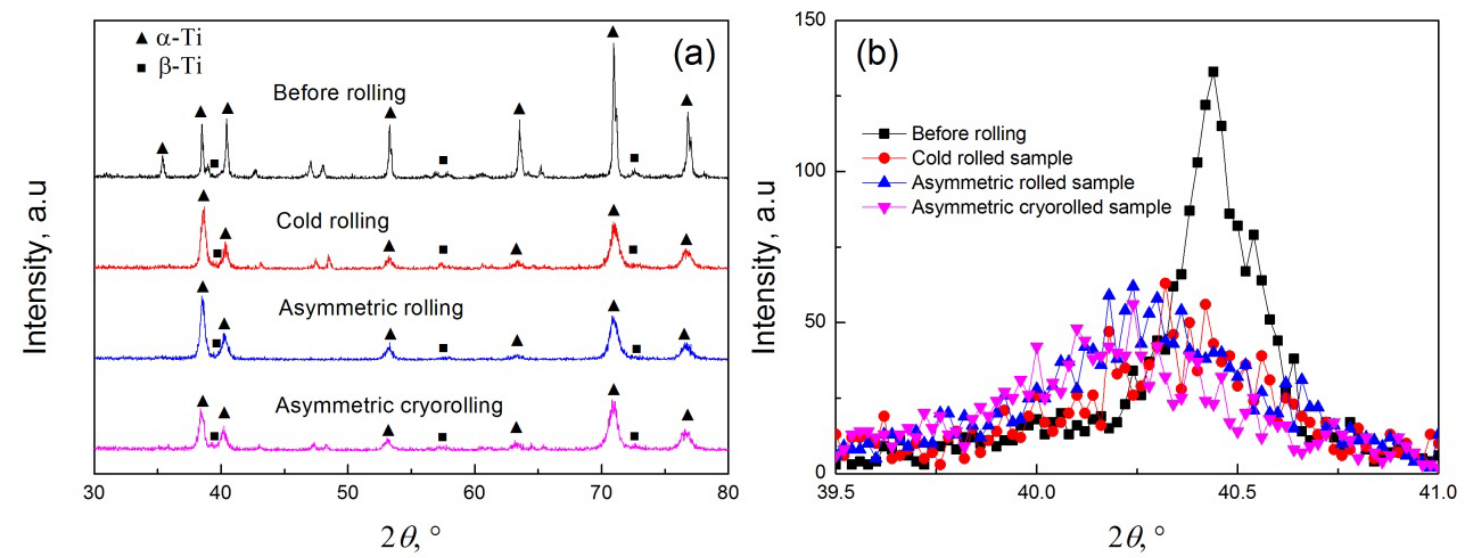

Fig. 7. (a) XRD results of the main phases of Ti-6Al-4V after different processes, (b) XRD results of Ti-6Al-4V for $39.5^{\circ}-41.0^{\circ}$. 
Table 1. Comparison of mechanical properties of Ti-6Al-4V alloy

\begin{tabular}{lccc}
\hline Samples & $\sigma_{\mathrm{b}}, \mathrm{MPa}$ & $\delta_{\mathrm{s}}, \%$ & Hardness, HV \\
\hline Standard Ti-6Al-4V alloy [6] & $\geq 930$ & $\geq 10$ & 348 \\
Cold rolled Ti-6Al-4V alloy & 1008 & 10.8 & 352 \\
Asymmetric rolled Ti-6Al-4V alloy & 1046 & 11.2 & 360 \\
Asymmetric cryorolled Ti-6Al-4V alloy & 1113 & 10.1 & 395 \\
\hline
\end{tabular}

Table 2. Thickness of $\mathrm{V}$ element assemble regions

\begin{tabular}{ll}
\hline Methods & Size, $\mathrm{nm}$ \\
\hline Cold rolling & $333.3 \pm 93.3$ \\
Asymmetric rolling & $245.3 \pm 98.9$ \\
Asymmetric cryorolling & $101.3 \pm 35.9$ \\
\hline
\end{tabular}

